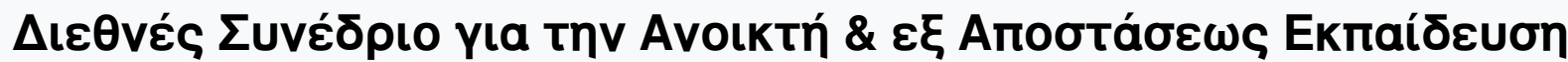

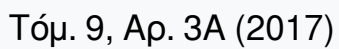

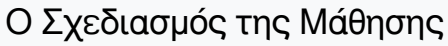

\section{Tónos 3, Mépos A}

\section{Практіка́}

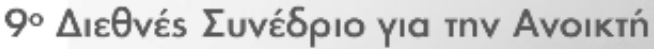

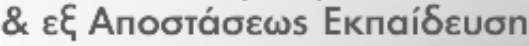

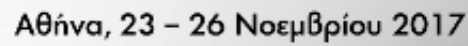

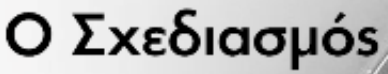 ins MáӨnons}

Enıе́̉̇eıa

Avióvns Aıvapákns

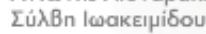

Mapia Niápn

Tké̉n Mavoúoou

Tóvıa Xaproqú

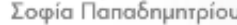

Avva Anoorodibou

ISBN 978-618-82258.8.6

ISBN SET 978-618-82258-5-5

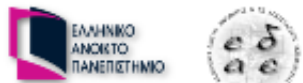

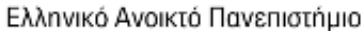

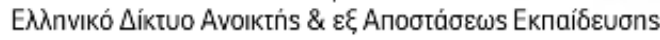

Distance Learning: Some parallels with conventional learning and administrative principles

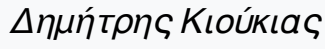

doi: $10.12681 /$ icodl. 920 


\title{
Distance Learning: \\ Some parallels with conventional learning and administrative principles
}

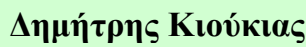 \\ $\Sigma \mathrm{E} \Pi / \Delta \mathrm{EO} 24$ \\ ЕАП \\ kioukias.dimitrios@ac.eap.gr
}

\begin{abstract}
Distant learning is often opposed to conventional learning, the latter often being signified by more physical proximity between teachers and students. Therefore, a comparison between the two forms of learning will, according to the previous argument, help better clarify the former. At the same time, this approach will help us understand the premises upon which distant learning may be based, probably some good old principles, aided albeit by new technology, which stand not far from general administrative principles tried nowadays.

Three areas of inquiry are chosen: "Distance", "Evaluation from below" and "Evaluation from above". Through this structure, in addition to exploring the main question, we get the opportunity to extract useful lessons about basic relationships between teaching staff and students as well as enrich our analytical methods, especially when we come to terms with coursework.
\end{abstract}

Keywords: distance learning, conventional learning, wider administrative principles, evaluation, new public management

\section{Introduction}

According to dialectics we better define and learn through comparing which means we need both different and opposite identities and concepts. For instance, we shall be able to obtain an accurate vision of Greek politics and society by studying not just the exact issue, but also politics and society in numerous countries, especially entirely different ones. It must be noted that this is Aristotelian logic and approach, as the Greek thinker is known to have studied about 150 different political systems, even if it is to wonder if there were actually so many different systems-surely there might well have been many city-states. This learning principle survived the ages and became an "eternal possession" for all humankind, whether low tech, or high tech.

In addition, "common sense" is often used as a minimum yardstick against which true or truism is measured, just like gold, silver and iron were tested upon the lydic stone in antiquity. Against such a test truisms, albeit grandiose and artistically made, were about to fall; they could not match truth in shinnying.

Distant learning is often opposed to conventional learning, the latter being signified by more physical proximity between teachers and students. Therefore, a comparison between the two forms of learning will, according to the previous argument, help better clarify the former. At the same time, this approach will help us understand the premises upon which distant learning is based, probably some good old principles, aided albeit by new technology. Internet itself is after all a wide shell which aspires to 
include all hereto accumulated knowledge. Besides being a communication medium, it is a great storage mechanism, a great promise, let me put it this way, that from now on nothing will be lost, everything will be saved to the benefit of humankind. That everything includes all past wisdom, methods and approaches which survived the waste time. If only there were an internet at the time the pioneering Greek philosophers wrote their works! There would exist much more of them. Markus Aurelius would have "lied" to us, as he condemned all "Gloria mundi" to forgetfulness.

But, by thus introducing you to our topic, we unintendedly have betrayed our method to you: this is no longer a conventional way of discussing such a subject. Well, maybe partly so, as when watching a relative introductory video course (MEAE 2015-16), I discovered that traditional kind teaching spirit! Adopting it we shall make some remarks on the issue our title suggest.

\section{Distant learning}

Just to innovate a little I have separated the word "distant" from the word "learning" using no language marks in between! Practically, learning in all its forms is associated with some sort of taking distance. A learning man or a woman is a distant person. Education is the opposite of instant action and the educated become kind of an aloof, as he/she is obliged to often close the door behind him/her, especially when he/she writes or watches someone or something (either a book or a monitor). This distance principle has survived all participatory calls which in late decades have been indeed "answered", either in politics, or art. Thus, every form of education is associated with distance, even in time, as the word "reflection" itself suggests: We reflect, we recollect, that is to say we rethink. Thinking most of the times becomes a historical study except for the rare cases we attend a teacher who speaks to us (the Open University's teaching sessions are really rare). Thinking is indeed rethinking, combining the new material with our already formed perceptions, i.e. logical tools of transforming "data" and sayings into communicable thoughts (communicable, first of all, to us). The knowledge of a language is after all an indispensable tool in order to take up a course. The better our grasp of the language, the more our grasp of the subject. In this case other variables such as the teacher, the books, the place and the room may be considered as "intermediary" variables, for no one is in a position to make for us a language, save for a scientific one (in which case every kind of participation in it greatly enhances our capabilities, e.g. through attending lectures, asking questions, etc. Education, it must be noted here, is not an accumulation of pieces of information, but, more than that, a systematic cultivation, especially of modes of expression, of gradually more complicated conceptual propositions).

In the era of globalization now distance has been presumably reduced. If in the early 19th c. you needed a couple of days to travel to a neighbouring prefect, today you get there just in an hour. Needless to say you communicate fast and in numerous ways within the "global village". Indeed we owe some innovating education institutions to technological advances. This, real or virtual, annihilation of distance is indeed a great progress, providing the populace with numerous education opportunities. Yet, it has not radically altered the old education process. You still need concepts (in order to abolish another kind of distance by creating shortcuts amidst the usually vast teaching material of a science-a totally descriptive teaching method would be a nightmare from this point of view), charts and graphs and traditional ways of constructing a communicable essay. A "powerpoint" is absolutely helpful, if used as an aid in specific cases, but only as a kind of snack when you do not find fresh food. Moreover, 
as learning time is quite limited, a very vertically structured and therefore elliptic method would make less room for both reflective and participatory methods. In other words, an abuse of a new method-tool may end up against vital time and space. Distance is still there-a table is a table, an abstraction!- but optimal use of time is not. This again may be a great loss if new technical methods are not used properly, but as a means which unjustifiably occupies space and time. Therefore, talking from our DL experience, though we often suggest to our students to use tables and other forms of summaries (1), we also urge them to develop other expressive tools (please note the above remark on education as a cultivation of complicated propositions).

At the same time, the issue in question takes us to the notion of hierarchy, sometimes pinpointed by some students. If one is to be responsible and accountable-providing some kind of good shape to a vast educational material- it must follow that he/she by definition is the chief organizer in a particular area (2). This idea is again associated with some kind of distance, for even in a crowd someone has to be discerned and distinguished as a chief organizer and a privileged speaker. Raising many doubts over his/her capacity to act like that looks like as a negation of the role itself and goes against any kind of organization (on the theory of the latter see Mouzelis 1967). Of course, official distance does not preclude participatory practices, especially when the organizer himself feels at home with them.

The latter remarks well guide us, as I believe, to a discussion of the evaluation from below practices.

\section{Evaluation from below}

One of the relatively new practices associated with distant learning, but not exclusively confined to it, is evaluation of the teaching staff by their students. If we are to give credit to the view that a holistic principle which just like a cloud shades all mini structures, the role of the lecturer becomes more managerial and political, at least in the sense that he/she must add to his tasks the management of quite a few social relationships. Though accountability has always been part of his duties- he has been an employee after all, this new form of accountability deducts from him part of his official power, for instance, the power of knowledge. He/she appears ab initio disputable, being subjected to occasional formal "objections" through a process of questioning. This again matches contemporary politicians' role who are subjected to numerous questionings through a variety of mechanisms and institutions (e.g. parliamentary committees, formal questioning time, anti-corruption committees, TV control, indirect control of private life, mass protests, international scrutiny of written and oral speech, etc., etc.).

This continuous questioning is among others supposed to comply with the notion of "clean politics", i.e. freed from corrupt practices. Social participation in official procedures is also thought useful towards this direction. This administrative principle is indeed a holistic one, permeating numerous social institutions, including of course educational apparatuses. Associated with it is also the notion of networking, i.e. calling various organized interests to have a seat or a say in official decisions.

Thus there has been established a principle of wider participation, of a quasi "public interest" in education and elsewhere. From this point of view, "evaluation from below" becomes understandable. It is a variation of the participatory principle which aspires to represent the "public interest" through a sort of periodic questioning of official teachers. But, as often student participation in lectures is not obligatory and flexible working terms are applied to the former, the principle may sometimes be compromised through various devices. For instance, the evaluation questions may be 
restricted to particular capacities, e.g. motivation or coordination and generally speaking managerial skills, leaving some core capacities described by CVs aside-quite rightly as students cannot interfere with such issues. Here again we encounter the incarnation of the managerial aspect of leadership!

In sum, the evaluation from below procedure requires teaching staff to develop quasi political-managerial skills and develop a kind of wider responsibility than a mere educational one (3). As we assume this is a holistic principle- we cited some examples above- it applies to both distant and conventional education, even if the latter may have not yet formally introduced evaluation from below procedures (at least in the public sector). Moreover, the principle may be quite workable, provided it is really concerned with concrete skills and named so (e.g. under the heading "evaluation of staff's managerial skills"). Finally, an attention should be drawn to the wider network, i.e. multiple interests or pre established relationships, i.e. political, local, etc. for they bear an impact on the main educational relationship. But by saying so we in fact reaffirm the quasi political role of the new teacher.

\section{Evaluation from above}

This is quite common in all tiers and kinds of education. As of lately the subjectivity factor had to be minimized (e.g. Hix 2004: 294), technical and standardized systems were applied here too. Quite often some quantifiable data are primarily employed as major indices of academic progress. They parallel economic production key criteria upon which governments' performance is based and measured. It comes close to the so called "management by targets" and is a kind of accountability based on easy to grasp and compare figures. As such the practice has acquired a normative character as it suggests what all institutions should do. For instance, (other) value judgments may be set aside, or subordinated to a minor role.

Even so, sometimes the writings themselves are obliged to acquire voice. This is evident in the system of examining essays which remains basic in the evaluation of social science student performance (especially when it comes to coursework which occupies the main terrain of course teaching. But, even modern political authority, despite all new technical restrictions, has to speak, not to mention the citizens. Along with the main channels of power (self)control and therefore structured discourse (cnf. with "politically correctness") we notice a multitude of political participation channels. This must be a talkative system as well. In case of excess there is the channel called internet social media which are expected to absorb part of citizen discontent and give chances for useful analyses and proposals. DL systems are more closely associated with such practices as they heavily rely on internet.

For all the technical suppression of direct talk and free rhetoric which used to flourish in the ancient regime, writing is still the basic unit for evaluation. This again has to be checked by experienced writers in the broad sense of the term; therefore writing competence -often officially assigned- seems to be a basic criterion for good examiners-evaluators. If one has written a good book, he/she will be expected to judge goodness in writing. Competence in difficult and complex issues which moreover are likely to make a wider impact is probably one of the criteria of "goodness". A good background and experience are pertinent too. In general what made past writers good and recognizable seems to be a standard criterion of competence in the form of a general guideline, mutatis mutandis. Furthermore, whether particular quantifiable data as for example market success or special distinctions can be evoked as an additional support source, it has often to do with 
factors pertinent to different kinds of national book markets, as some perform more independently than others (e.g. they are less accountable to the political regime).

Good and bad are correctly described in Greek Open University relative lists (e.g, Kokkos \& Lionarakis 1998: 251). For example, according to such criteria, a good essay has to meet both formal criteria and criteria of substance with the latter considered as the most important ones. Innovation, rhythm and expression, critical and analytical ability, substantiation are some of the key criteria. At the same time, any intentions towards faking and deceiving are being considered as mere penalties and plagiarism is electronically checked. Thus, from this point of view, it follows that artificially overblown works do not comply with criteria of goodness. What is faked is still a devaluated entity- technological progress has not changed that. Let it be hoped such kind of educational authority will be transmitted to the other social structures and contribute to the discounting of mere instrumental practices (Bell 1968, Baudrillard in Cahoone 1996: 437-460), (4)..

Finally, it is essential to avoid particular misinterpretations-in my view another characteristic of modern times, to be probably attributed to the spirit of continuous innovation underlining modern economy, ethics or intellectual atmosphere. As therefore some meanings have been wrongly connected with others, innovation has sometimes become synonymous to eccentricity. Yet the latter denotes some kind of mixing up words, meanings and other forms of representation and (self) expression a phenomenon which if abused certainly leads to a grotesque kind of affairs. However, eccentricity, grotesque, innovating and originality are not equal. When, for instance, we want to introduce some new scientific terms we are obliged to what thus far has been offered in this area and try to cite all synonym terms, explaining why the newest term is better and more accurate. Innovation, besides, should not be concerned just with terms (signifiers), but meanings (signified). We still use old languages and all good works have not deviated from this norm. Their originality lies in the shining of ideas, to use that old expression. To accumulate a lot of similar terms is like encouraging the phenomenon of rewriting a law upon a similar law (something which modern legal and political norms try to combat); or, like writing a "new" book which already exists as a meaning and essence.

In sum, to try to innovate is to try to exhaust the research of a subject and dare attack the unspeakable, if we can! At the student level this old educational principle means a will to take initiative, to dare, for instance, to initiate a conversation, new data, or our own combination of meanings. As students, we most of the times virtually rewrite History, but we hold the right to put it in our own words, once we pass the test of the already spoken (for example, once we have added a few paragraphs of relative literature review). An exercise on moving thought, a short Odyssey in the chambers of sea will be the best testimony, the best certificate of our own "tenure" in "distance learning"!

\section{Conclusion}

Writing a conclusion is often a burden. What is the use of repeating in a few words what we have already said? Is it probably a mere formality? A formal conclusion may not be that far from that. A more serious conclusion is perhaps a kind of art, as one is asked to encapsulate in some sort of aphorisms a bulk of pages. Yes, in the concluding section we may become more definitive, more sure, more sculptors than essay writers-for we normally deduct, we do not add. Yet, we can also add. A good film without a strong ending is an imperfect one, just like a technological tool which offers a lot, but puts you at risk. Therefore, we must find the courage to continue, to 
end! Encouragement is after all a cornerstone of DL systems, because of distance! Now, we have to encourage ourselves, no mobiles, no internet now, lost in the universe by some chance (yes, we are permitted some lyricism at this stage ...).

In conclusion then, though new technologies and some brilliant ideas-le this not be forgotten- contributed to the advancement of DL, some measure of distance has always been associated with education. A French writer, Alain, used to say that "our ideas are our spectacles" (in Sartori 1987: ix), meaning by that that we form our perceptions about things through what we learn, but also that between the "objective world" and the subject-student there is always some distance -symbolised by the word "spectacles". For, if education were non intermediated- say by the ideas of the books and the teaching staff- it would be instant and ready to consume.

Technology makes things look instant-the speed of our access to bibliographical resources has been multiplied; still we are in need of reflection and "re-writing".

Some other key principles of conventional education (e.g. marking papers and evaluating) cannot also been avoided. To the degree DL changes some established norms that quite often responds to major structural changes in the politicaladministrative environment. "Governing without government" (Rhodes 1996), for example, matches learning without a formal teacher. The latter is still there, but partly transformed into a manager-tutor very much like a contemporary prime minister "coordinates" a common programme.

Though we have moved towards an ethics of result (a term coined by Max Weber), in an effort to get rid of superfluous rigidities which used to hold us back in most social spheres, we also witness a tendency toward magical automation, bypassing some essential educational preconditions. Magic here is to be understood as a culture of rapid results which have to bypass some classical reasoning as well accountability related to reasoning (5). For instance, we wish to abruptly evaluate teachers using minimal symbols, i.e. marks (e.g. in evaluation from below cases). However, we need to take into account some content-qualitative factors which may be not part of relative questionnaires. How, for example, could we expect student-evaluators to decide on the published work of a professor? We rightly have bypassed such issues in evaluation forms; but then we ripe just some results, we get imperfect results. Fortunately, the values of accountability and reasoning are quite entrenched in DL systems in the case of evaluation from above. Through them we can transform instrumental values and "instant education" into a real distance education.

\section{Footnotes}

(1) A summary looks modern in an era of brief statements due to a customary worship of time-globalization has been often depicted as synonymous to a shrunk time. However, it also looks ancient, as the Greeks and Romans admired short and accurate speech, often taking the form of short sayings-aphorisms. Moreover, from this point of view, a "summary" or a "conclusion" measures our ability to express a lot through few lines, to be some sort of poets! (See on such matters Kioukias 2014). In addition, to reach the conclusions is the same as to deduct as well as better shape, as if I had to sculpt out of a vast material. In a rather curious way what is modern has to go back to that old art of abstraction-conclusion is an abstraction!

(2) Here the framework of analysis echoes the modern notion of leadership as management. I tend to believe that the assignment of managerial roles to public officials including the prime minister himself came about mainly due to the process of further democratization which swept the planet after the end of Cold War. It, so our argument goes, went hand in hand with the transformation of the state into a "public 
management". Though the latter is often ascribed to the rise of technocracy, it also reflects democratic aspirations, as the notion of pure management is "liberated" from shades of hierarchical power often associated with the notion of "leadership". Closely related to this conceptual transformation is the notion of the "strategic state" and "governing without government" (On the prime minister as a "manager" see Moschopoulos 2008: 44. For instance, while, according to the text, the prime minister "coordinates", "defines", or intermediates, he never governs directly. On the other concepts usedhere see...

(3) Besides, universities and schools today have assumed a wider role; they have been drawn to the national and international economy and are expected to contribute to it (e.g. to raise money, to invest, cooperate with other local economic agencies, etc). This role had been added to the older political one. For instance, judging from the Greek experience (from other national experiences too), major university officials are loosely or tightly tied to the political arena. It is for such reasons that strictly academic selection and evaluation criteria cannot be enforced. This question has lately prompted across Europe taking depoliticization measures across a wide spectrum of public administration. Moreover, technical evaluation measures have been introduced which lead to quantification and standardization. It is hoped though that such kind of minimization will not be at the expense of content evaluation. At the end of the day promotion is a kind of recognition by human beings. Thus, while the efforts to objectify some basic criteria are worthwhile, good performance is to be decided upon real "works", i.e. texts. In the educational unit I happened I have been a member they have rightly decided that a good part of students performance is based on pre established major guidelines but also subjective interpretation and implementation. Subjectivity, of course, is in such cases mediated and reduced by staff selection processes, much like political representatives are, first, Elected from a party determined list. That means that they must meet some basic qualification criteria. This kind of pre election is of course combined with some other control institutions normally applied in post election stages. However, a good degree of authority and responsibility is a measure of political and educational freedom. In this case the room of subjectivity allowed is the same as talking about the room of individual competence, indispensable for memory and thought and maximization of contribution. Where little room is left for individual creation innovation is not to be expected. Imitation is more probable.

(4) D. Bell had long time ago suggested that what was at that time described as "postindustrial society" was largely characterized by instrumental values such as the need to consume knowledge as If it were a commodity. J. Baudrillard contributed to this discussion through his notion of "simulacra", i.e. a trend towards reproducing and consuming images, artware, ideas. Actualizing at all costs has become a trademark of late modernity. Perhaps, the technical means availed today make us adopt a sort of instrumentality, to satisfy our needs and desires as quickly as possible. We tend to become oriented towards "results". "Innovation" under such circumstances becomes a synonym to the word "results", something (e.g. a patent) which will be easily used and consumed. A "results oriented management" has helped, of course, to overcome bureaucratic and other rigidities of the past. This is the good aspect of instrumentality. Sometimes, however, we need to take care of some costs of it such as careful and safe design of products is. For a hastily made innovation may cause unexpected damage. At the same time, in order for a new formula to become workable and sustainable we need to test it seriously and not superficially. Yet, it is this shorttermism that forms the dominant mode in nearly all areas of social life. From this 
point of view, the sociological school of "risk societies" should, in my view, include the risks of the spirit of such kind of experimentation.

(5) According to Bergson magic is the desire and attempt to influence things and persons from afar in such a way as to bring about the results we wish (developed in http: //dkioukias.blogspot.com). For a revival of magic in modern societies see Mouzelis 2014: 39.

\section{Abbreviation \\ $\mathrm{DL}=$ Distance Learning}

\section{Bibliographical refereneces}

Akalides, S. \& Moschopoulos, D. (2008), The Greek Public Administration, the Hellenic Open University (in Greek).

Bergson, The Two Sources of Morality and Religion (in Greek).

Baudrillard, J. (1996). "Symbolic Exchange and Death" in L. Cahoone, From Modernism to Postmodernism, An Anthology, Blackwell.

Bell, D. (1968). The Coming of Post-industrial Society, New York, Basic Books.

Hix, S. (2004). “A Global Ranking of Political Science Departments”, Political Studies Review, vol. 2, 293-313.

Kioukias, D. (2011-17). "keimena-ka", personal blog, http://dkioukias.blgspot.com

Kioukias, D. (2014), Philosophical Rhythms, Athens, Papazisis, ebook (in Greek).

Kokkos, A. \& Lionarakis, A. (1998), Open and Distance Learning: Relationships between teachers and taught. Patra, Hellenic Open University (in Greek).

MEAE (2015-16). Unit of Internal Evaluation and Training, video course, Greek Open University.

Mouzelis, N., (1967), Organization and Bureaucracy, PhD thesis, published by Routledge \& Kegan Paul, London.

Mouzelis, N. (2014), Modernity and Religiosity, Athens, Polis (in Greek).

Rhodes, R.A.W. (1996), "The New Governance: Governing without Government", Political Studies, $44(4)$,

Sartori, J., (1987), The Theory of Democracy Revisited, New Jersey, Chatham House. 